\title{
Extreme variations in the ratios of non-synonymous to synonymous nucleotide substitution rates in signal peptide evolution
}

\author{
Federico Garcia-Maroto*, Atilio Castagnaro, Pilar Sanchez de la Hoz. Carmen Maraña**, Pilar \\ Carbonero and Francisco García-Olmedo
}

Bioquimica, Biología Molecular. E.T.S. Ingenieros Agrónomos.UPM. E-28040 Madrid, Spain

\begin{abstract}
Nucleotide sequences encoding signal peptides from the precursors of x-amylase:trypsin inhibitors from cereals are homologous to those corresponding to the precursors of thaumatin 11 and of plastocyanins. Non-synonymous $\left(K_{f}^{\prime}\right)$ and synonymous ( $K_{S}^{\prime}$ ) rates of nucleotide substitutions have been calculated for all possible binary combinations. Extreme variation in $\mathcal{K}_{\mathrm{A}} \cdot \mathcal{K}_{\mathrm{s}}$ talios has been observed; from the 0 .l67 average found within the plastocyanin fatmily to an average of 1.90 calculated for the inhibitors:thamatin [] transition. A similar calculation has heen carried out for the signal peptide sequences of thionins. which a re unrelated to those of the $x$-amylase trypsin inhibitor tamily, and an average $K_{4}$ : $K_{5}$ of 0.12 has been obtained. This variation can be largely explained in terms of an empirical index of stability related to atmino acid composition and seems to be independent of functional constrainis.
\end{abstract}

x-Amylase; trypsin ithibitor: Thaumatin II: Thionin: Plastocyanin; Signal peptide evolution

\section{INTRODUCTION}

It has been repeatedly observed that the rates of synonymous nucleotide substitutions $\left(K_{S}\right)$, which do not lead to amino acid changes, are greater than those of non-synonymous substitutions $\left(K_{\mathrm{A}}\right)$ which do cause such changes, and that both rates are greater in pseudogenes (see $[1,2]$ ). These differences in substitution rates have been ascribed to selective constraints related to structure-function relationships. Thus, func:tionally constrained proteins or parts of proteins would evolve at a slower rate than less constrained ones, and residues at functionally important positions should be less variable than those at other positions (see [3]). A number of cases have been reported in which the spatial distribution and the rate of amino acid substitution do not seem to follow these rules [4-8]. Positive Darwinian selection has been involved to explain the accelerated changes taking place at functionally relevant sites in these cases, all of which involve familjes of proteinase inhibitors. However, an alternative explanation has been proposed that is consistent with the neut ral theory of evolution [3]. The alternative explanation is in agreement with the contention that the mutability of an amino acid is determined not so much by its position, but by the consequences of its being replaced on the overall chemical and spatial structure of the protein [9].

In the course of our study of two plant protein families, the $\alpha$-amylase/trypsin inhibitors and the thionins (for reviews, see $[10,11]$ ), we have observed extreme variation in the rates of change of their signal peptides. These peptides, which determine the cotranslational translocation of the corresponding mature proteins across the endoplasmic reticulum membrane, have some common features, such as an N-terminal methionine, charged amino acids near the $\mathrm{N}$-terminal, and a membrane-spanning hydrophobic sequence, but are otherwise highly variable among different genes and can be considered of polyphyletic origin [12]. However, different genes may code for homologous signal peptides that co-evolve with their neighbouring mature proteins. We report here an analysis of substitution rates in the signal peptide sequences of the two protein families which indicates that the observed variation can be explained to a great extent by compositional effects consistent with the neutral theory of evolution.

\section{MATERIALS AND METHODS}

Nucleotide sequences encoding signal peptides of the precursors of (x-amylase/trypsin inhibitors were determined by direct sequencing of he cloned sDNAs. Sequences, sloning and screening procedures corresponding to $D$ DNAs not presiously reported will be published elsewhete. Appropriate references for those already reported are given in the legend of Fig. 1 .

A comptler program kindly donaled by W.H. Li (Houston. Texas) was used to estimale the rates of synonymous and non-synonymous nutleotide substitution [13|. The Microgenie Program (Beckman) was used to search for homologous sequences encoding signal peptides. 
(A)

\begin{tabular}{|c|c|}
\hline $\begin{array}{l}\text { INH FCT? } \\
\text { E'L BAR }\end{array}$ & 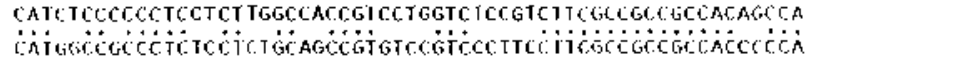 \\
\hline $\begin{array}{l}\text { INEI PNIS? } \\
\text { THA }\end{array}$ & 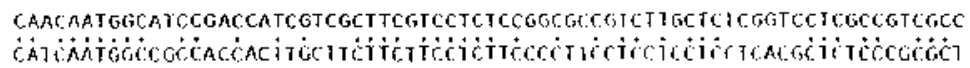 \\
\hline
\end{tabular}

(B);

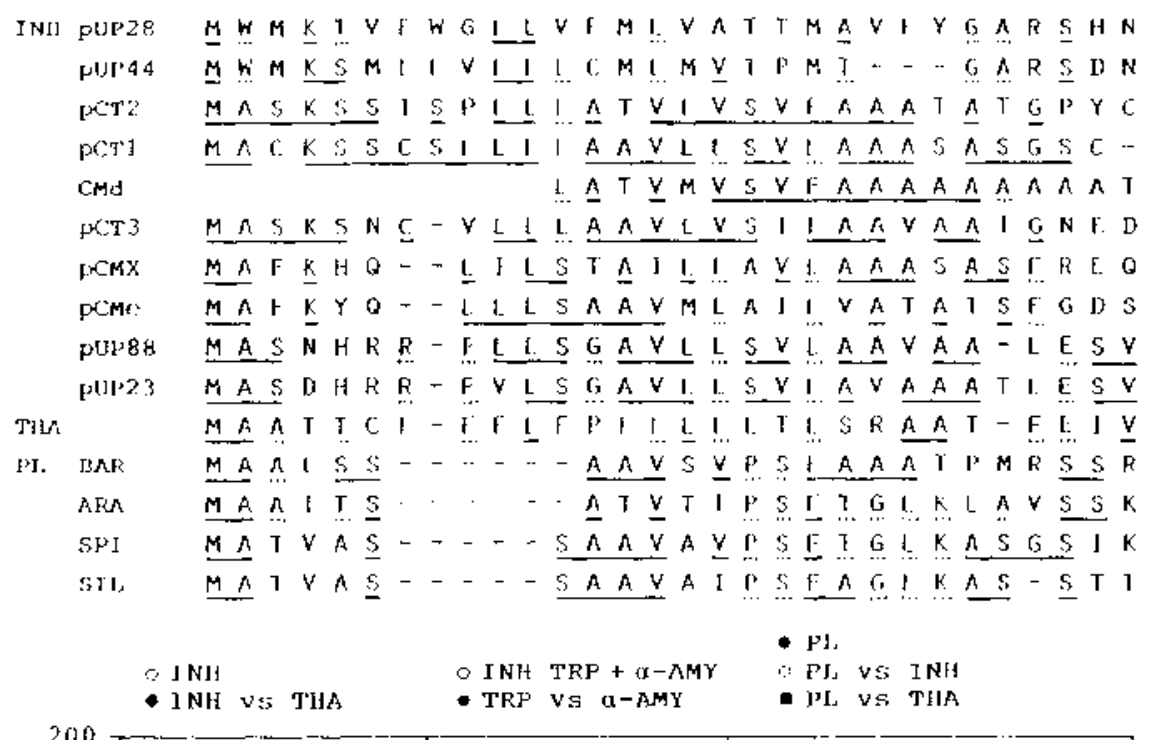
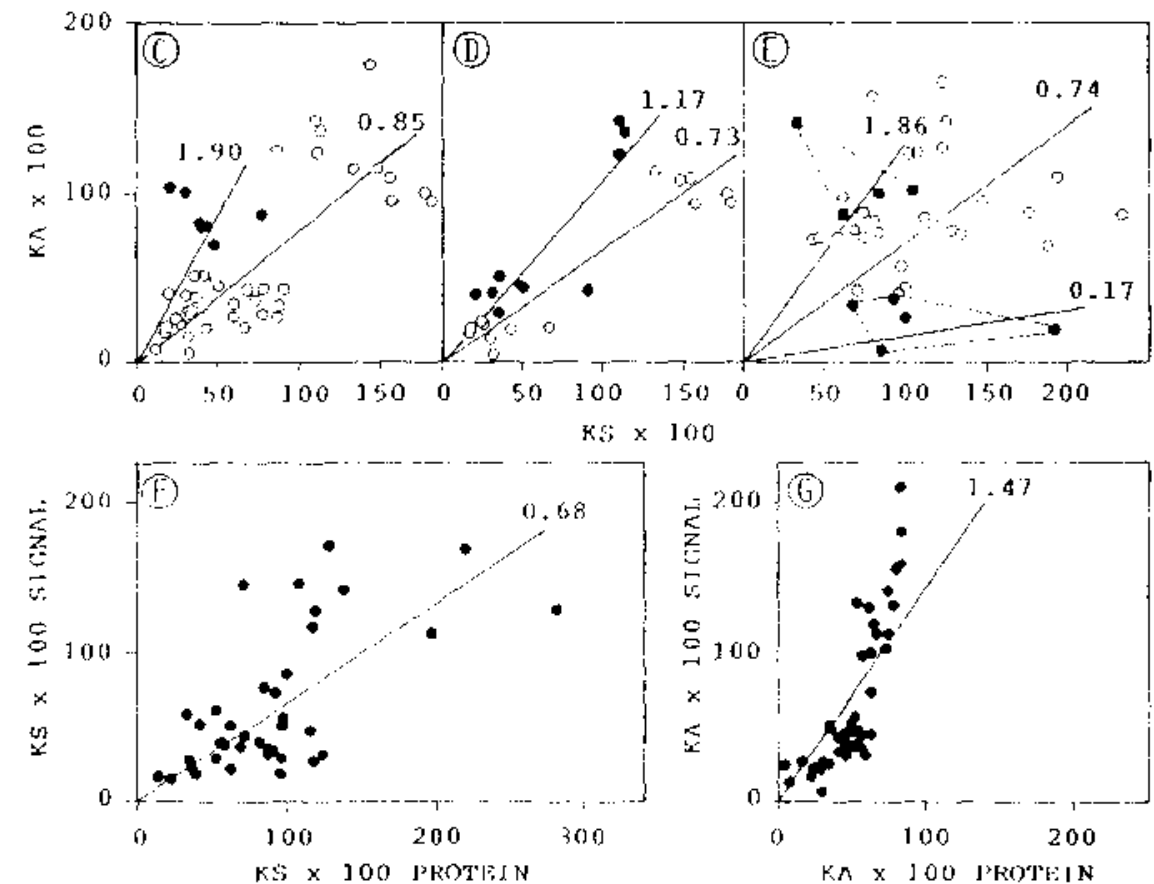

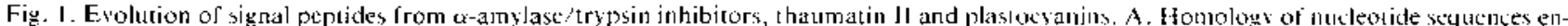

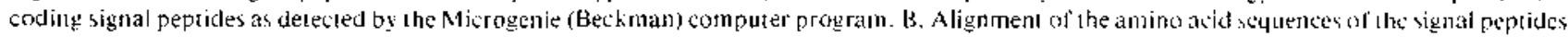
used to calculate $K_{A}$ and $K$, with the compucer programme of $\boldsymbol{K} . \mathrm{H}$. Li. The most frequent residues at a given position are underlined. $1-$ and

...). ('-E. Representation of $K_{S} \times 100$ v's $K \times 100$ values for the indicated binary combinations ol signal peptides. The numbers indicate atcrage

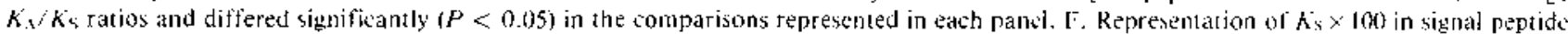
's $\mathcal{A}_{4} \times 100 \mathrm{in}$ adjacent protein sequence. $G$. Representation of $K_{+} \times 100$ ol signal peptide is $K_{4} \times 100$ of adjacent protein. The inhibitor family (JNH) includes mhibiors of trypsin (TRP) and $\alpha$-amylase ( $\alpha$-A.MY), as well as womponents whose activily has not been idencilied. INH sequences

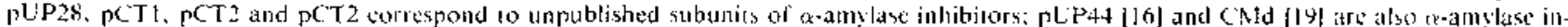

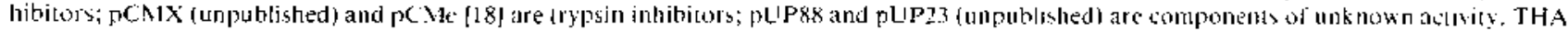
corresponds to thaumatin II [17.21]. Plastocyanin (PL) sequences werc frem the Mitrogenie data base (PLA96 ifom barley, BAR; PLA30 irom Arabidopsis thationa, ARA; PI.A869 from spinach, SPI; PLA7(22 from Silente pratensis, SIL). 
Statistical significance of differences belween average $K_{\checkmark} / K_{\mathrm{S}}$ ratios was calculated using the non-parametric Mann-Whitney test. The in. dex of mutability derived by Graur [9] ior the 7 relevant amino acids was calculated using the fotmula $I,=0.841-5.096 \mathrm{f}$ (ily $+24.145 \mathrm{f}$ Asn $-26.807+\mathrm{Tyr}-7.398 \mathrm{f} \mathrm{Val}-18.219$ i Phe -8.263 f Asp +7.960 ille.

\section{RESULTS}

The $\alpha$-amylase/trypsin inhibitor family in wheat and barley includes monomeric, dimeric, and tetrameric inhibitors of heterologous $\alpha$-amylases, as well as trypsin inhibitors, and is encoded by genes dispersed over several chromosomes [10]. These inhibitors are synthesiced by membrane-bound polysomes as precursors in which the mature proteins are preceded by typical signal peptides, as shown by a study of their synthesis in vivo and in vitro [14] and by cloning and sequencing several cDNAs [15-20]. Homology was found between the signal peptides of the inhibitors and those of two other plant protein classes, thaumatin $11[17,21]$ and plastocyanins [22-25] using the Microgenie Computer Programs, Beckman (Fig. 1A). In Fig. 1B, the signa] peptides of ten members of the $\alpha$-amylase/trypsin inhibitor family have been aligned with those corresponding to thaumatin II [21] and to four plastocyanin clones [22-25]. Based on this alignment, both synonymous and non-synonymous nucleotide substitution rates have been estimated for all possible binary combinations, using the computer programme of $\mathrm{Li}$ [13]. The $K_{\mathrm{A}}$ and $K_{\mathrm{S}}$ values obtained within the inhibitor family and between members of this family and thaumatin II are represented in Fig. 1C. The $K_{\mathrm{A}} / K_{\mathrm{S}}$ ratio for each group was calculated as the slope of a least-squares-adjusted line intersecting the origin. This ratio was quite high for the signal peptide within the inhibitor family and significantly higher in the transition from the inhibitors to thaumatin II. Values obtained within the trypsin inhibitor and $\alpha$-amylase inhibitor subfamilies can be compared with those obtained in binary combinations involving one member of each subfamily in Fig. 1D. Similarly, in Fig. IE, values obtained within the plastocyanin family are represented together with those corresponding to plastocyanin/inhibitor and plastocynin/thaumatin II combinations. The signal peptide of the inhibitor is evolving faster than the adjacent mature protein sequence, i.e. lower $K_{\mathrm{S}}$ (Fig. 1F) and higher $K_{\mathrm{A}}$ (Fig. 1G).

In contrast with the above observations, the thionin signal peptide (Fig. 2A) is evolving at a slow rate (Fig. 2B), which is even slower than that of the adjacent mature protein, with lower $K_{\mathrm{S}}$ (Fig. 2C) and still lower $K_{\text {A }}$ (Fig. 2D).

\section{DISCUSSION}

The data presented here indicate that amino acid sequences with a common functional constraint in their evolution, i.e. their function as signal peptides, show extreme variation in their $K_{A} / K_{\mathrm{S}}$ ratios. Graur [9] suggested that the propensity of an amino acid to remain conserved in the course of evolution depends not so much on its being in functional sites, but on an intrinsic

(A)

\begin{tabular}{|c|c|c|}
\hline T.aestivum & $\begin{array}{l}r 1 \\
\alpha_{2}\end{array}$ & MG--SKGLKGVMVCLLI ILGLVLEQVOVEG \\
\hline H. vulgare & $a$ & LKGVMVĆLLILGLVLEQVOVEG \\
\hline & B & -MVC̄LLILGLLEHVOVEG \\
\hline & DB 4 & MA-PSKS I KSVVICVLILGLVLEOVOVEG \\
\hline & DC4 & $\overline{M M}-P S X S I K S V V I C V L 1 L G L V L E O V O V E G$ \\
\hline & DG3 & VICVL]LGLVLEOVOVEG \\
\hline & Gl & ] KSVV[CVL]LGLVLEOVOVEA \\
\hline & $\mathrm{G} 2$ & 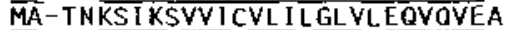 \\
\hline
\end{tabular}
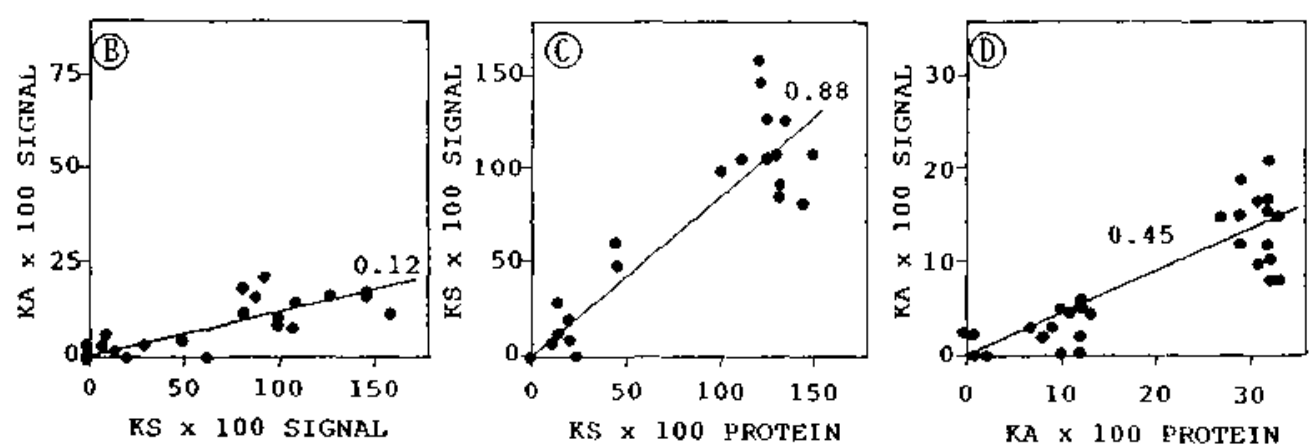

Fig. 2. Evolution of signal peprides from the thionin family. A. Alignanent of known parts of signal peptides used to calculate $K_{4}$ and $K_{S}$ with the computer programme of W.H. Li. B. Representation of $K_{4} \times 100 \vee 5 K_{\$} \times 100$ values of signal peptides. C. Representation of $K_{\$} \times 100$ of signal peptide vs $K_{3} \times 100$ of adjacent protein. D. Representation of $K_{4} \times 100$ of signal peptide $v s K_{A} \times 100$ of protein. $\alpha 1$ and $\alpha 2$ fron 7 riticum aesivim (unpublished). as well as $\alpha$ and $i$ from $H o r d e m$ pitgare $[25,26]$ are endosperm thionins, while the ochers are from leaves [2 8,29$]$. 
Tabli 1

Values of the mutability index $t_{11}$, taking into account the frequencies of the following 7 amino acids (f:r: Cily, Asn, Tyr, Val, Plut, Asp, lle

\begin{tabular}{|c|c|c|}
\hline Seỵtence & Abtores: & Value \\
\hline \multicolumn{3}{|l|}{ Signal peptides } \\
\hline Thaumatın & Tha-sP & 4.637 \\
\hline Average inthibilor: & Inli-SPar & 1.455 \\
\hline Areage plistrocyanins & PI-SPas & 1.121 \\
\hline Average thionins & Thi-SPay & 0.825 \\
\hline \multicolumn{3}{|l|}{ Nature proteins } \\
\hline Avcrage inhibitors & Juhar & 0.629 \\
\hline Alcrage thioning & Thiar & 1.0 .36 \\
\hline
\end{tabular}

stability index defined as the mean chemical distance between the amino acid and its mutational derivatives produced by a single nucleotide substitution. Reliable predictions of mutability could be obtained with an empirical index $I_{\mathrm{m}}$, based on multiple lincar regression equations involving the frequencies of particular amino acids in a given sequence $[3,9]$. The $/$; values for the signal peptides studied here (Table l) rank in the order Tha-SP $>$ Inh-SPav $>$ PI-SPav $>$ Thi-SPav, which are in line with the calculated $K_{N} / K_{S}$ values. Similarly, InhSPav>Inhav and Thi-SPav< Thiav, as expected from the $K_{d}^{\prime} / K_{S}$ ratios. These results indicate that at least an important fraction of the observed variability in $K_{\mathrm{V}} / K_{\mathrm{s}}$ ratios can be considered as consistent with the neutral theory.

In three situations, the non-synonymous rate $\left(K_{A}\right)$ significantly exceeds the synonymous one $\left(K_{S}\right)$; the inhibitor/thaumatin II transition (Fig. 1C), the trypsin inhibitor/ $\alpha$-amylase inhibitor transition (Fig. ID), and the plastocyanin/thaumatin II transition (Fig. IE). In the first and third cases, the transition implies a change in the mature protein partner served by the signai peptide, while in the second case, a change of activity of the mature protein has occurred. A similar situation has been described by Hill and Hastie [4] in a comparison of the putative reactive center and the neighbouring $5 \mathrm{c}$ quences of a given serpin in rat, mouse, and man. Positive Darwinian selection was invoked by these authors to explain observed high rates of evolution, but Graur and $\mathrm{Li}$ [3] subsequently interpreted the same dat a in terms of compositional effects. In the present case, the data suggest a significant acceleration in the transitions.

Acknowledgements: Technical assistanci from D. Lamoneda is gratefully acknowledged. Work was supporfed by Citant BIO\&8-0216 from the Comision Inlcrministerial de ('iencia y: Teconologia (Spalin).

\section{REFERENCES}

(1) Li, W..H., Gojobori, T. and Nei. M. 11981 ) Nature 292, 237-239.
[2] Niyala, I, and Yandedsal, T. (I) $78,450-453$.

[3] Giaur, O. and Li. H..H. (1988) I. Not. Exol, 28, 131-135.

[4] Hill, R.E. alli Hastic. N.D. (l9887) Niturti 326, 96-99.

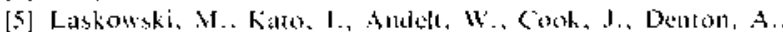
Empic, N.H.. Kobr, H.J., Park, S.J., Parks, K., Shateley. H.I... Schoentherger. O.L., Tashíro, M., Vithod. (j., Whatey,

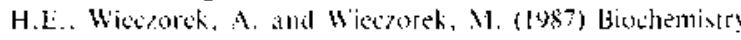
26, 2012-221.

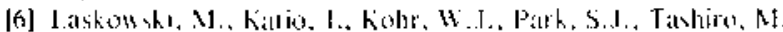
and Whates, H.t. (1987) Cold Spring Hashor Symp. Quant. Bicl. 52, 201 -207

[7] Fïroli, F.., Jacopino, Gi.. Angedeni, M., Barra, D., Bossa, F and Ascoli, F. (1985) I. Biol. Clum. 260.1145]-1]455.

[8] Crejghton. T.L. and Charle', I.(i. 1987) I, Mol, Biol. 194, II-Is.

19] (iraur, D. 119851 J. Mol. Evol. 22, 53-62

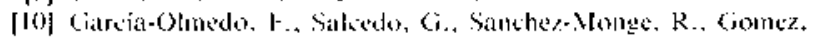

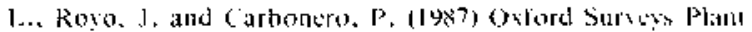
Mol. Cell Biol. 4, 275-334

[1I] Ciarcia-Olumedo, F., Rodriglez-Palcozacla, P., Hermandez. l.utals, C., Ponz, I., Mararia, C., C'mmona, M.J., L.opez. Fando, I., Femander, I.A. and Carbonero, P. (1989) Oxlord Surver Plan Mtal. Cell Biol. 6, 31-60)

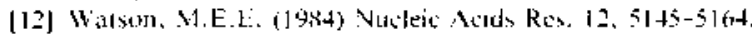

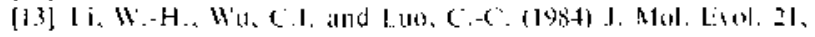
$58-71$

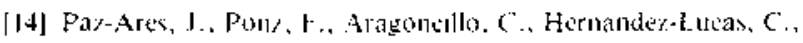
Sakedo, Ci.. Carbonero. P. and Giarcia-Olmedo. F. (I983) Planta $157,7+-80$

[15] Pat-Ares, J.. Ponz, Iः, Rodriguez-IPalenzucla, P., Lafaro, A., Hernánder. Lucas, ( , , Gartia-Olnedo and Carbonero, P', (1986) Theor. Appl. [ience. 7], $8+2-k+k$

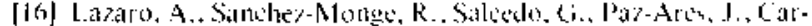
bontero. P. and (sartia-Olmedo, F. (I988) Eur. I. Biochen. I72. $129-134$.

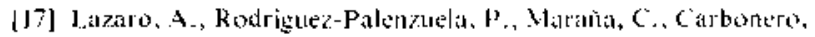
$P$, and Gaccia-Olmedo, F. (1984) FEBS l.e.1. 239, 147-150.

[18] Rodtiguez.Palenzucla, P.. Roso, I., Giomes, I.., SitnchezNonge, R, Salcedo. G., Molina-Cano, , I. . Cialicia-OMncdo, I: and Carbonero. P. (1989) A10l. Crene, Cicnco. 219, 474-474.

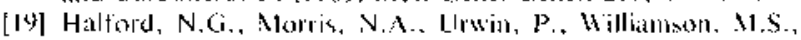

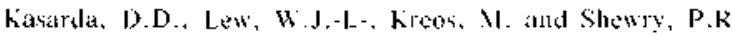
(1958) Biochim. Biophys. Aclil 950, +35-440.

[20] Gartia-Narolo, F., Maraña, C., Mlena, M., Ciarcia Olmedo, F and Carbonero. P. \{1990) Plant Nol, Biol. 14, 845-853.

[2I] Edens, L.. Heslingar, I.., Klok, R. I.eclebost, A...., Maa, I..

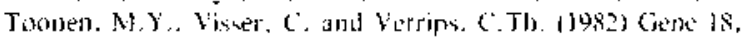
$1-12$.

[22] Smeckens, S., de Ciroon. MI., an Bunsberen, J. and Wisbeck, P. (1985) Natule $317,456-458$.

[23] Rouher, C.. Jansen, T. Tyagi, A., Tilngen, I, and Herrmann. R.G. (1986) Curt. Genct, 11, 171-176.

[24] Vorst. O.. Oosicthoff-Tecristra, R., Vankan, P.. Smetekens, S and Weisbeek, P. (1988) (iche 65.59.69

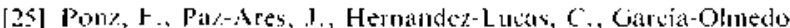
$\mathrm{I}$, and Carbonero. P. (1986) E(tr. 1. Bionhem, 156, 131-1.3.5

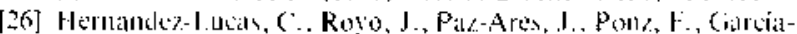

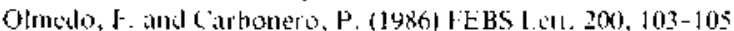

[?7] Rodriguez-Pulemzleda, P. Pincor-[oro. I.A. Carboneto, P and Carria-Olmedo, F. (1988) Geme 70, 271-28]

[28] Gausing, $K$, 11483) Planra 17t, 241-246

[29) Bohlmant], H. and Apel, K. (1987) vol. Cien. (jelkel, 207 446-454. 